NBER WORKING PAPER SERIES

\title{
PAPER MILLIONAIRES: HOW VALUABLE IS STOCK TO A STOCKHOLDER WHO IS RESTRICTED FROM SELLING IT?
}

\author{
Matthias Kahl \\ Jun Liu \\ Francis A. Longstaff \\ Working Paper 8969 \\ http://www.nber.org/papers/w8969 \\ NATIONAL BUREAU OF ECONOMIC RESEARCH \\ 1050 Massachusetts Avenue \\ Cambridge, MA 02138 \\ June 2002
}

\begin{abstract}
We are grateful for helpful discussions with David Aboody, Mark Garmaise, Robert Geske, Mark Grinblatt, Robert Merton, Lisa Meulbroek, and Richard Roll, and for the comments of seminar participants at the University of California at Berkeley and California State University at Fullerton. We are also grateful to Brent Longsta .and Eric Neis for research assistance. We are particularly grateful for the comments and suggestions of the editor Bill Schwert and an anonymous referee. All errors are our responsibility. The views expressed herein are those of the authors and not necessarily those of the National Bureau of Economic Research.
\end{abstract}

(C) 2002 by Matthias Kahl, Jun Liu and Francis A. Longstaff. All rights reserved. Short sections of text, not to exceed two paragraphs, may be quoted without explicit permission provided that full credit, including (C) notice, is given to the source. 
Paper millionaires: How valuable is stock to a stockholder who is restricted from selling it?

Matthias Kahl, Jun Liu and Francis A. Longstaff

NBER Working Paper No. 8969

June 2002

JEL No. G11

\begin{abstract}
Many firms have stockholders who face severe restrictions on their ability to sell their shares and diversify the risk of their personal wealth. We study the costs of these liquidity restrictions on stockholders using a continuous-time portfolio choice framework. These restrictions have major effects on the optimal investment and consumption strategies because of the need to hedge the illiquid stock position and smooth consumption in anticipation of the eventual lapse of the restrictions. These results provide a number of important insights about the effects of illiquidity in financial markets.
\end{abstract}

Matthias Kahl

The Anderson School

UCLA

Box 951481

Los Angeles, CA 90095-1481
Jun Liu

The Anderson School

UCLA

Box 951481

Los Angeles, CA 90095-1481
Francis A. Longstaff

The Anderson School

UCLA

Box 951481

Los Angeles, CA 90095-1481

and NBER

francis.longstaff@anderson.ucla.edu 


\section{Introduction}

In recent years, the number of stockholders suffering huge losses during market downturns while liquidity restrictions prohibited them from selling their shares has skyrocketed. ${ }^{1}$ These types of restrictions are widespread, affecting entrepreneurs, venture capitalists, private equityholders, corporate officers, managers, and many others. For example, lockup restrictions are often imposed as part of the initial public offering (IPO) process. More broadly, however, selling restrictions are usually included in executive stock or stock-option based compensation contracts. In addition, Rule 144 of the U.S. Securities and Exchange Commission (SEC) places severe restrictions on the ability of most corporate insiders and affiliates to sell shares in their firm. Because of these restrictions, some stockholders bear the costs of holding an illiquid undiversified portfolio for many years.

Although the benefits of liquidity restrictions in retaining key employees and managers and in reducing agency conflicts are well understood, the costs imposed by these restrictions have been largely unexplored. Accordingly, the goal of this paper is to examine how selling or liquidity restrictions affect the welfare of stockholders. Since these stockholders often have a substantial stake in their venture, we will refer to them simply as entrepreneurs throughout the paper to make the intuition more clear. To study the effects of liquidity restrictions, we model the optimal consumption and portfolio choice problem of an entrepreneur who owns stock in a firm, but is unable to sell this stock for a given period of time. In addition to this restricted stock, the entrepreneur has liquid wealth which he can allocate between the stock and bond markets. This feature is important since it allows the entrepreneur to take a stock market position that offsets some of the risk of his illiquid stockholdings and reduces the cost of the restrictions. Note that allowing the entrepreneur to invest in other markets differentiates this paper from earlier work (primarily focusing on executive stock options rather than restricted stock) in which agents are not allowed to hedge their undiversified positions in other markets (for example, see Hall and Murphy, 2000b). This framework also allows us to study how the consumption level (or lifestyle) of an entrepreneur is affected by liquidity restrictions. The welfare loss due to the liquidity restrictions is calculated by comparing the maximal utility achieved by the entrepreneur with that achievable if the stockholdings were fully liquid.

${ }^{1}$ There are many examples of entrepreneurs, managers, and others with significant stockholdings, initially worth millions on paper, who lost most of their wealth without ever being allowed to sell any of their stockholdings. See the recent articles on the effects of selling restrictions on inside stockholders in The Wall Street Journal on March 23, 2001, April 12, 2001, April 25, 2001, and May 17, 2001, and in Businessweek on April 17, 2000, and April 16, 2001. 
The results indicate that the cost of liquidity restrictions can be surprisingly large. For example, when stock is restricted for five years and represents $50 \%$ of his wealth, an entrepreneur would actually be better off if he could sell his restricted stock for $30 \%$ to $80 \%$ of its unrestricted market value. Furthermore, these costs can be significantly higher when nearly all of the entrepreneur's wealth is tied up in restricted shares and when the entrepreneur is not able to hedge his restricted shares with offsetting stock market positions. These results contradict the widely held practitioner view that restricted stock has only a minor cost to the recipient (see Wall Street Journal, April 12, 2001, p. R1) and is a much more efficient form of compensation than executive stock options. These costs are roughly on the same order of magnitude as those reported in studies of the cost of awarding executive stock options such as Hall and Murphy (2000a, 2000b) and Meulbroek (2001). ${ }^{2}$ The results also indicate that the cost of liquidity restrictions tends to be higher for agents who are more risk averse. If the ability to innovate is not the same as the ability to bear risk, however, this implies that liquidity restrictions may discourage risk averse (but potentially highly productive) agents from entrepreneurial ventures. Furthermore, these results suggest a possible basis for explaining the large valuation discounts associated with private equity placements (see Wruck, 1989; and Silber 1992) and contribute to the growing literature on the effects of illiquidity on security values. ${ }^{3}$

We find that owning restricted shares can have a dramatic effect on the optimal portfolio strategy for the liquid portion of the entrepreneur's portfolio. Depending on the firm's correlation with the stock market, the entrepreneur can significantly increase or decrease his stock market holdings. This effect is largest when the restricted shares represent an intermediate fraction of the entrepreneur's wealth. Interestingly, even when the correlation between the firm and the stock market is zero, the entrepreneur can hold more of the stock market than he would in the absence of liquidity restrictions. Intuitively, this is because taking additional stock market risk helps smooth consumption variability caused by the temporary liquidity restrictions. Finally, we show that even though the entrepreneur can borrow against his illiquid position, he chooses to consume at a much lower rate than he would without liquidity restrictions.

This analysis also has implications for several areas in corporate finance. The

\footnotetext{
${ }^{2}$ Meulbroek (2001) uses an approach based on equalizing the Sharpe ratio between the market and the illiquid stock to compute the discount. This preference-free approach is easily applied and can be viewed as providing a lower bound on the discount for the illiquid stock. We are grateful to Robert Merton for this insight.

${ }^{3}$ For example, see Mayers (1972, 1973), Grossman and Laroque (1990), Amihud and Mendelson (1991), Boudoukh and Whitelaw (1991, 1993), Kamara (1994), Longstaff (1995, 2001a, 2001b), Vayanos (1998), Huang (1998), and Brenner, Eldor, and Hauser (2001).
} 
model suggests that restricted stock can be worth substantially less to managers who have a large fraction of their wealth invested in their company and face significant trading restrictions. This makes it a more costly corporate governance tool and less effective at reducing agency costs. Although we focus on restricted stock, this implication is consistent with recent results in the executive stock option literature. For examples of this literature, see Lambert, Larcker, and Verrecchia (1991), Rubinstein (1995), Aboody (1996), Carpenter (1998, 2000), Hall and Murphy (2000a, 2000b), and Meulbroek (2001). Moreover, the high cost of the lack of diversification associated with concentrated managerial equity ownership gives managers a strong incentive to make diversifying acquisitions even if not in the interests of their shareholders (see Amihud and Lev, 1981; and Morck, Shleifer, and Vishny 1990). Minimizing these costs can also provide an important motivation for taking a firm public. Furthermore, the cost of these restrictions help explain the growing use of diversifying strategies such as zero-cost collars and equity swaps documented by Bettis, Bizjak, and Lemmon (2001). Finally, La Porta, Lopez-de-Silanes, and Shleifer (1999) show that in most countries, family ownership is the dominant ownership structure even for the largest publicly traded firms. Our model suggests that the costs imposed on the family owners due to a lack of diversification can be significant. In an insightful recent paper, Hong and Huang (2001) argue that investor relations efforts by firms may be motivated by the goal of increasing trading volume and thereby relaxing liquidity restrictions on corporate insiders.

The remainder of this paper is organized as follows. Section 2 describes a number of ways in which different types of liquidity restrictions arise. Section 3 presents the dynamic portfolio choice model. Section 4 examines the effects of liquidity restrictions on welfare and optimal consumption and portfolio decisions. Section 5 discusses the implications of the results. Section 6 makes concluding remarks.

\section{Liquidity Restrictions}

There are many reasons why a shareholder might not be able to sell his shares for an extended period of time. In this section, we describe a number of common situations in which shareholders are subject to these types of selling or liquidity restrictions.

First, there are many situations in which selling restrictions are imposed by contract, often to resolve moral hazard and adverse selection problems. One example that has attracted substantial interest in the recent academic literature is that of stock lockups in IPOs (see Brav and Gompers, 2000; Ofek and Richardson, 2000; and Field and Hanka, 2001). These lockups are not required by the SEC, but are

part of the contract between the issuer and the underwriter in the vast majority of IPOs. Most lockups do not allow company insiders (officers, directors, employees, 
their friends and family, and venture capitalists) to sell their shares for a period of 180 days. This restriction could be lifted for individual trades by the underwriter in an early release, but this typically affects only a small fraction of the stock held by insiders (Brav and Gompers, 2000). The lockup period, however, can be longer than 180 days. For example, Ibbotson and Ritter (1995) report that Morgan Stanley agreed to a two-year lockup period in its IPO.

The literature offers several economic reasons for IPO lockup provisions. First, they provide a signal of the value of the company, as suggested by Welch (1989), and modeled by Brau, Lambson, and McQueen (2001). Lockups make it less likely that the shares are sold to the public shortly before the release of negative information about the firm. Brav and Gompers (2000) argue that the variation in the length of the lockup period and the number of shares retained are systematically related to the uncertainty about the firm's value. Similarly, Longstaff (1995) argues that IPO underpricing could be partially due to the effects of lockup provisions. The lockup period gives key employees and management an incentive to ensure good corporate performance, at least until the insiders can sell their stock. Adding to the importance of trading restrictions associated with insider share ownership in IPOs, it is often the case that management and active investors (such as venture capitalists) are subject to additional vesting agreements that go beyond the lockup period (Ofek and Richardson, 2000).

Lockup or vesting periods play a similar role in managerial compensation contracts. Many firms use restricted stock plans as part of the compensation package. In these plans, managers receive a specified number of shares in the firm, but cannot sell these shares for a given period of time. Moreover, the shares are forfeited if the executive leaves the firm before the restriction period is over. Kole (1997) finds that 79 of 371 Fortune 500 firms in her sample have such restricted stock plans. The average minimum holding period before any shares can be sold ranges from 31 months for firms with a medium level of research and development to 74 months for firms with a high level of research and development. For more than a quarter of the plans, the stock cannot be sold before retirement. The rationale for these minimal holding periods is that it provides managers an incentive to take actions that increase the long-term value of the firm, not just the short-term value. Furthermore, this tool is used to increase managerial retention by creating substantial switching costs since the restricted stock plan typically becomes void upon the departure of the manager.

Minimal vesting periods also typically apply to executive stock option plans, which require the executive to hold the options for a prespecified time before exercising them. In Kole (1997), the average minimum waiting period before any of the options can be exercised is 13.5 months. The average waiting period before the options can be exercised (taking into account that some fraction of the options can be exercised after the minimum waiting period, but the remainder only after an additional waiting period) is 23.6 months. 
Another example where individuals obtain stock that cannot be sold for a certain period is in a merger agreement where the target's key employees and managers obtain restricted stock in the combined company. Typically, such restricted stock also comes with a lockup period during which it cannot be sold. The motivation is similar to that for trading restrictions in executive compensation contracts. The liquidity restrictions are intended to align the interests of the target's key employees and managers with the combined company and also give them an incentive to stay with the combined company. This is of particular importance when the value of the target company lies primarily in the human capital of its key employees, which is likely the case in many start-ups. Finally, Bettis, Coles, and Lemmon (2000) find that over $92 \%$ of the firms in their sample impose limitations on trading by corporate insiders such as blackout periods during which trading is not allowed.

In addition to contractual restrictions, however, corporate insiders often have significant liquidity restrictions imposed on them for legal reasons. These legal restrictions can be even more stringent than the contractual restrictions. In some cases, the legal restriction begins at the time the contractual restriction lapses and significantly extends the period of illiquidity. In general, a shareholder must satisfy both the legal and contractual restrictions before selling this stock.

An important example of a legal restriction is SEC Rule 144 which limits the amount of stock a corporate insider or affiliate can sell without registering the transaction. Under the Securities Act of 1933, any person who sells a security to another person must register that security with the SEC unless a statutory exemption can be found for the transaction. Since the registration process can be prohibitively expensive and time consuming for many security holders, SEC Rule 144 was designed to enable the public sale of limited amounts of unregistered securities under certain conditions. These conditions are intended to avoid situations where securities are acquired by an underwriter with a view to distributing them to the public without going through the formal registration process. Since individual investors who are not professionals in the securities business can be "underwriters" under the meaning of the Securities Act, Rule 144 provides a safe harbor by which sales of unregistered securities will not be construed as sales by an underwriter. Osborne (1982) provides further discussion of the economic rationale provided by the SEC for Rule 144. The cost of achieving this safe harbor, however, is that the securityholder must hold the securities for a number of years, presumably to signal that the securities were not acquired primarily to distribute them to the public without making the disclosures required by the registration process.

The holding period required under Rule 144 depends on whether the security holder is defined as an affiliate of the corporation. Affiliates include officers of the corporation such as the CEO, president, senior officers, directors, spouses of officers, relatives living in the same home as the officer, any persons in a position to exert influence such as members of an officer's family or close associates, and owners of 
$10 \%$ or more of the voting shares. Note that the definition of an affiliate is somewhat broader than that of a corporate insider. Stock held by an affiliate is termed control stock, and affiliates are often referred to as control persons.

Control stock can be acquired in a number of ways. For example, stock can be acquired through compensation arrangements, exercise of stock options, payment for professional services, venture capital arrangements, partnership distributions, private placements, or even open market purchases. Rule 144 prohibits an affiliate from selling restricted control stock for one year after the stock is acquired. After the one-year period, however, there are a number of limitations placed on an affiliate who wishes to sell control shares. Specifically, the affiliate is only allowed to sell an amount of stock during any three-month period equal to the greater of one percent of the total amount of shares outstanding or, if the firm is listed on a stock exchange or quoted on Nasdaq, the average weekly reported trading volume in those shares over the four weeks preceding the potential sale. Thus, for many smaller and lessactively traded firms, it can take many years before a control shareholder is able to completely liquidate a substantial equity stake in the firm. In addition to these volume restrictions, current financial information must be available regarding the company whose securities are being sold. An affiliate must also file Form 144 with the SEC for larger proposed sales. For a nonaffiliate, similar liquidity restrictions apply to their sales of restricted or unregistered stock, but only during the first two years after the stock is acquired. There are many other examples of liquidity restrictions imposed by law such as the rules prohibiting insiders from trading during periods surrounding earnings announcements.

Finally, since the effect of liquidity restrictions on insiders is to increase the concentration of their holdings in the firm, this analysis is relevant for the issue of concentrated ownership in general. Specifically, ownership of many firms is concentrated in the hands of a small number of investors, who often have a large fraction of their wealth invested in these stocks. This is true for private equity as documented by Moskowitz and Vissing-Jorgensen (2001). Moreover, La Porta, Lopez-de-Silanes, and Shleifer (1999) find that in most countries, the most common form of ownership is family ownership, even for the largest publicly traded firms.

\section{The Model}

In this section, we model the portfolio choice of an agent where some portion of his wealth is in shares that he cannot sell for a given period of time. An example of this would be a corporate manager or entrepreneur who receives compensation in the form of shares, but is prohibited from immediately selling those shares and rebalancing his portfolio. To make the intuition as clear as possible, we use a simple but realistic portfolio choice framework in which there are three types of assets: a 
riskless bond, a stock index fund, and the restricted stock that the entrepreneur holds. This partial equilibrium framework is a simple generalization of the standard Merton $(1969,1971)$ continuous-time framework.

Let $B_{t}$ denote the value at time $t$ of a riskless bond or money market fund with dynamics given by

$$
d B=r B d t
$$

where $r$ is the constant riskless interest rate. Let $M_{t}$ denote the value of a risky asset which can be viewed either as the stock market or a share in a stock index fund. The dynamics of $M_{t}$ are given by

$$
d M=(r+\mu) M d t+\sigma M d Z_{1},
$$

where $\mu$ is the market risk premium and $\sigma$ is the volatility of returns. Both $\mu$ and $\sigma$ are positive constants.

Although the entrepreneur is not allowed to trade his shares in the firm, we assume that shares in the firm can be traded by others who are not subject to the restriction. Let $S_{t}$ denote the market value of a share of the firm's stock. We assume that the dynamics of $S_{t}$ are given by

$$
d S=(r+\lambda) S d t+\nu S d Z_{2},
$$

where $\lambda$ is the excess expected return for the firm and $\nu$ is its volatility. Again, both $\lambda$ and $\nu$ are positive constants. The correlation between $d Z_{1}$ and $d Z_{2}$ is $\rho d t$, where $-1<\rho<1$. This allows for the important possibility that returns on the market and on the firm's stock are (potentially highly) correlated. To focus more directly on the effects of liquidity restrictions, we make the simplifying assumption that the risk premium $\lambda$ is given by the Capital Asset Pricing Model, implying that $\lambda=\mu \rho \nu / \sigma$. An immediate implication of this assumption is that an unconstrained entrepreneur would want to hold the firm's stock only to the extent that it appears in the stock index. This implies that the unconstrained optimal portfolio weight for the firm's stock is zero.

The entrepreneur has an investment horizon of $T<\infty$, and at time zero, is given $N$ shares of stock in his firm. To capture the essence of the liquidity restriction, we assume that the entrepreneur cannot change the number of shares of stock he holds until time $\tau \leq T$. This is consistent with actual practice where shareholders are typically not allowed to change their position either directly by selling stock, or indirectly by trading options or entering into equity swaps or similar types of derivative contracts. After time $\tau$, however, the entrepreneur can trade his shares 
in the firm without restriction. While the number of shares $N$ the entrepreneur holds does not change until time $\tau$, the proportion of his wealth held in the form of illiquid stock is stochastic. Let $X_{t}=N S_{t} / W_{t}$ denote the portfolio weight for his illiquid stockholdings, where $W_{t}$ denotes his total wealth at time $t$. Since $N$ is assumed to be positive, $X_{t}>0$ for all $t<\tau$. Longstaff (2001a) studies the optimal portfolio choice problem in a model where an agent can only trade limited amounts of a risky security per unit time. In an independent paper, Henderson and Hobson (2001) develop a model similar to ours in which an agent is unable to trade shares and offer a series-based approximation for the optimal solution that is valid only for small values of $X$. Our model differs from theirs, however, in that we allow for intermediate consumption. In addition, we study the effects on consumption and portfolio choice for general values of $X$.

The entrepreneur has preferences given by

$$
E\left[\int_{0}^{T} e^{-\kappa s} U\left(C_{s}\right) d s+e^{-\kappa T} U\left(W_{T}\right)\right]
$$

where

$$
\begin{aligned}
U(x) & =\frac{x^{1-\gamma}}{1-\gamma}, & & x \geq 0, \\
& =-\infty, & & x<0,
\end{aligned}
$$

and where $C$ denotes consumption, $\kappa$ is the rate of time preference, and $\gamma$ is the risk-aversion parameter. The entrepreneur's liquid wealth is given by $\left(1-X_{t}\right) W_{t}$, which he allocates between the riskless asset and the stock market. Let $\phi_{t}$ denote the portfolio weight (as a percentage of his total wealth) for the stock market. Since portfolio weights sum to one, the portfolio weight for the riskless asset is $1-\phi_{t}-X_{t}$.

In this framework, we allow the entrepreneur to take unlimited short positions in both the riskless asset and the stock market. A review of industry practice indicates that some investment firms allow investors to borrow a limited amount of funds on the security of their restricted stockholdings. In fact, a number of financial firms specialize in what is termed Rule 144 lending. In actuality, however, it is easily shown that if the entrepreneur allows his liquid wealth to become negative, then there is a possibility of reaching negative total wealth. Intuitively, this happens because once the value of the liquid part of the entrepreneur's portfolio becomes negative, there is a non-zero probability that it will remain negative. Furthermore, there is always a possibility that the illiquid stock will decline in value towards zero before the liquidity restriction lapses. Thus, the entrepreneur's total wealth could become negative if $X$ becomes greater than one. Since this implies an expected utility of negative infinity in this model, the entrepreneur never chooses an investment strategy that allows 
liquid wealth to become negative. Thus, the entrepreneur never borrows against illiquid stock, which implies that $0<X \leq 1$ for all $t<\tau$.

Following Merton (1969, 1971), the entrepreneur's wealth follows the dynamic process

$$
d W=((r+\mu \phi+\lambda X) W-C) d t+\sigma \phi W d Z_{1}+\nu X W d Z_{2}
$$

The entrepreneur's dynamic decision problem is to choose his consumption $C_{t}$ and the portfolio weight for the stock market $\phi_{t}$ in a way that maximizes his expected utility subject to the dynamic budget constraint in Eq. (5). Allowing the entrepreneur to make optimal portfolio choices is essential in estimating the cost of liquidity restrictions. In particular, simple certainty-equivalence approaches which do not allow agents to select portfolios optimally can actually produce negative estimated costs, implying the counterfactual result that restricted securities are worth more than unrestricted securities. For example, Hall and Murphy (2000b) provide a further discussion. As in Merton, we define the entrepreneur's indirect utility of wealth function to be

$$
J(W, X, t)=\max _{\phi, C} E\left[\int_{t}^{T} e^{-\kappa s} U\left(C_{s}\right) d s+e^{-\kappa T} U\left(W_{T}\right)\right]
$$

The Appendix shows that when $t<\tau, J(W, X, t)$ can be expressed in the form

$$
J(W, X, t)=\frac{W_{t}^{1-\gamma}}{1-\gamma} F(X, t)
$$

and that the first-order conditions for the optimal consumption level $C^{*}$ and the optimal investment in the stock market $\phi^{*}$ are respectively,

$$
\begin{aligned}
C^{*} & =W\left[e^{\kappa t}\left(F-\frac{X}{1-\gamma} F_{X}\right)\right]^{-\frac{1}{\gamma}}, \\
\phi^{*} & =\frac{-\frac{\mu}{\sigma^{2}}(1-\gamma) F+\left(\frac{\gamma \rho \nu}{\sigma}+\frac{\mu}{\sigma^{2}}\right) X F_{X}+\frac{\rho \nu}{\sigma} X^{2} F_{X X}}{-\gamma(1-\gamma) F+2 \gamma X F_{X}+X^{2} F_{X X}}-\frac{\rho \nu}{\sigma} X .
\end{aligned}
$$

The function $F(X, t)$ satisfies a Hamilton-Jacobi-Bellman equation which is given in the Appendix. Because expected utility equals $-\infty$ if $X$ exceeds one, $F_{X}(1, t)=\infty$ is required to hold at the boundary $X=1$. Although $F(X, t)$ cannot be solved in 
closed form, standard finite difference or simulation techniques can be applied to provide numerical solutions for $J(W, X, t)$ and the values of $C^{*}$ and $\phi^{*}$. Because of the nonlinearity of the Hamilton-Jacobi-Bellman equation, standard existence and uniqueness results for the solution cannot be applied. Thus, it is important to acknowledge that in providing numerical estimates of the solution, we are implicitly assuming that a solution exists and abstracting from uniqueness concerns. When $t \geq \tau$, the liquidity restriction is no longer binding, $X$ equals its unconstrained optimal value of zero, and $J(W, X, t)$ takes on the functional form $J(W, t)$ since it no longer depends on $X$ (the solution for $J(W, t)$ is given at the end of this section).

From the first-order conditions, the entrepreneur's optimal consumption level $C^{*}$ and portfolio weight $\phi^{*}$ are nonlinear functions of $X$. Despite this, some intuition about the optimal strategies can be obtained by considering the structure of the problem. In particular, when the entrepreneur faces no liquidity restrictions, utility is maximized at every instant by solving a local mean-variance optimization problem. In contrast, when the entrepreneur faces liquidity restrictions, the decision problem can be viewed as a blend of a buy-and-hold problem with a standard problem of continuous rebalancing, which means that the entrepreneur must now also consider global portfolio changes.

Another way of seeing this is by noting from Eq. (5) that the dynamics of the entrepreneur's wealth are completely determined by the values of $\phi, X$, and $C$. When the entrepreneur faces no liquidity restrictions, the entrepreneur is free to choose any values of $\phi, X$, and $C$, which gives full control over the distribution of wealth. Because one can optimize choices of $\phi, X$, and $C$ individually, the optimal values of these controls have the simple functional forms obtained by Merton (1969). When there are trading restrictions, however, the initial value of $X$ is given exogenously and the entrepreneur can only choose the values of $\phi$ and $C$. In this case, $\phi$ and $C$ now play dual roles in maximizing the entrepreneur's utility. Specifically, $\phi$ and $C$ affect the dynamics of wealth directly as before. However, the values of $\phi$ and $C$ affect the behavior of $X$ over time, which has an indirect effect on the dynamics of wealth. For example, choosing a lower level of current consumption tends to reduce future values of $X$. When there are liquidity restrictions, both the direct and indirect effects of $\phi$ and $C$ on the distribution of wealth must be considered in maximizing the entrepreneur's utility. Not surprisingly, this makes the optimal values of $\phi$ and $C$ depend on $X$ in very subtle and complex ways.

Despite this complexity, however, several comparative statics results can be given. For example, as $X \rightarrow 0$, the optimal portfolio weight $\phi^{*}$ converges to the constant portfolio weight $\frac{\mu}{\gamma \sigma^{2}}$ given in Merton (1969). As $X \rightarrow 1$, both $\phi^{*}$ and $C^{*}$ converge to zero. The intuition for this is that if the entrepreneur's liquid wealth were to reach zero, the entrepreneur would need to prevent liquid wealth from becoming negative. Thus, the entrepreneur would avoid any further market risk in the liquid portfolio by placing zero weight in the stock market. Furthermore, the entrepreneur 
would forego consumption rather than borrowing against illiquid wealth and creating a negative liquid wealth position. In actuality, the entrepreneur's optimal consumption and investment strategies serve to insure that liquid wealth remains positive. By guaranteeing that liquid wealth is always nonnegative, the entrepreneur's optimal consumption and portfolio strategies also insure that total wealth is always nonnegative. Dybvig and Huang (1988) show that requiring wealth to be nonnegative eliminates unrealistic strategies such as the doubling strategy discussed by Harrison and Kreps (1979).

In the special case where $\mu=\gamma \rho \sigma \nu, \phi^{*}$ reduces to $\rho \nu(1-X) / \sigma$, which implies that the optimal portfolio strategy is a simple linear function of $X$. Finally, note that the second term on the right hand side of Eq. (9) represents minus the amount of the market portfolio "embedded" in the restricted stock. To see this, recall that the stock return can be decomposed into two components: a component equal to the stock's beta times the return on the market, and an idiosyncratic component. Thus, a position in the stock with portfolio weight of $X$ has the same exposure to the market as a position in the stock index with portfolio weight $\beta X=\frac{\rho \nu}{\sigma} X$. This means that the total effective position in the market equals $\phi^{*}$ plus $\frac{\rho \nu}{\sigma} X$, or simply the first term on the right hand side of Eq. (9). ${ }^{4}$

To evaluate the welfare loss to the entrepreneur of being constrained to hold $X$ percent of wealth in the form of restricted stock, we compare $J(W, X, t)$ with the derived utility of wealth that the entrepreneur would have in the absence of any liquidity restrictions, which we denote $J(W, t)$. Again following Merton $(1969,1971)$, the Appendix shows that the unrestricted derived utility of wealth $J(W, t)$ can be expressed as

$$
J(W, t)=\frac{W_{t}^{1-\gamma}}{1-\gamma} e^{-\kappa t}\left[\frac{\gamma}{\theta}\left(\left(1+\frac{\theta}{\gamma}\right) e^{\frac{\theta(T-t)}{\gamma}}-1\right)\right]^{\gamma},
$$

where

$$
\theta=(1-\gamma)\left(\frac{\mu^{2}}{2 \gamma \sigma^{2}}+r\right)-\kappa
$$

The optimal consumption and portfolio strategies in the absence of liquidity restrictions are also provided in the appendix. Finally, we note that when $t \geq \tau$, the liquidity constraint is no longer binding and the indirect utility of wealth function $J(W, X, t)$ reduces to the function $J(W, t)$ given in Eq. (10).

\section{The Effects Of Liquidity Restrictions}

\footnotetext{
${ }^{4}$ We are grateful to the referee for this insight.
} 
In this section, we study the effects of liquidity restrictions on the entrepreneur. We focus first on the welfare effects of these restrictions and estimate their economic costs. We then examine how liquidity restrictions affect the optimal portfolio decision. Finally, we consider how the optimal consumption policy changes when there are restrictions.

\subsection{The cost of liquidity restrictions}

The fundamental issue that needs to be addressed is how the entrepreneur's overall welfare is affected by liquidity restrictions. The welfare costs of these restrictions can be calculated directly by simply contrasting the entrepreneur's derived utility of wealth $J(W, X, t)$ in the presence of liquidity restrictions with the derived utility of wealth $J(W, t)$ corresponding to the case where there are no restrictions.

In comparing the values of $J(W, X, t)$ and $J(W, t)$, we use the following intuitive metric. Specifically, we solve for the implied value of the restricted stock at which the entrepreneur would be indifferent between continuing to hold restricted shares, or selling them and then investing the proceeds plus liquid holdings without restrictions. We then compute the ratio between this implied value and the market value of stock. For simplicity, we will refer to this ratio simply as the implied value of the restricted stock. Table 1 reports these ratios for different values of the risk-aversion coefficient $\gamma$, the beta of the firm $\beta=\rho \nu / \sigma$, the volatility of the firm's returns $\nu$, and for different levels of $X$ and $\tau$. These values are chosen to provide a cross section of realistic possible scenarios. For example, we consider illiquidity horizons of one, two, and five years. These horizons represent the length of time that an entrepreneur with a significant stake in the firm might need to sell a position. In addition, Table 1 considers volatilities for the firm of $30 \%$ and $60 \%$. These volatilities are consistent with those recently experienced by many individual Nasdaq stocks. Fig. 1 graphs the implied stock values as functions of $X$ for various combinations of the parameters.

As shown, the implied value of restricted stock to a entrepreneur facing liquidity restrictions can be significantly less than its unrestricted market value. For example, when the entrepreneur has a risk-aversion coefficient of two, the illiquidity horizon is five years, and the restricted stock represents $50 \%$ of total wealth, the implied value of a dollar of restricted stock ranges from 42 to 82 cents. Similarly, when the entrepreneur has a risk-aversion coefficient of four, the illiquidity horizon is five years, and the restricted stock again represents $50 \%$ of total wealth, the implied value of restricted stock ranges from 30 to 70 cents. As illustrated, the costs of illiquidity can be significantly larger when the restricted stock represents nearly all of the entrepreneur's wealth. As discussed earlier, an entrepreneur with a large stake in an infrequently traded start-up venture could easily find these examples representative of his situation. The magnitude of these implied costs are clearly on the same order of magnitude as the implied costs associated with executive stock options. For example, Hall and Murphy (2000b, p. 11) find that executive stock options are only worth $40 \%$ to $60 \%$ of their Black-Scholes value. Similarly, Meulbroek (2001) argues 
that executive stock options are only worth 53 to 70 percent of their Black-Scholes value. These results indicate that the impact of illiquidity on restricted stock values can be just as severe as on executive stock option values. This is important given the widely held belief among practitioners that restricted stock is far more valuable to recipients than are stock options (for example, see Wall Street Journal, April 12, 2001, p. R1).

The implied value of restricted stock as a fraction of market value is a decreasing function of $X$. This is intuitive since the greater the value of $X$, the more binding is the liquidity constraint. The effect of the diversification constraint is compounded by the length of the liquidity restriction. Table 1 shows that as the length of the liquidity restriction horizon grows from one to five years, the implied value of the restricted stock can decrease more than proportionately. This effect is particularly evident for high values of $X$. The results indicate, however, that the interplay between $X$ and $\tau$ is complex. The interaction between the illiquidity horizon and the percentage of illiquid assets depends nonlinearly on the parameters.

The results in Table 1 also illustrate that the implied value of restricted stock is a decreasing function of the level of the entrepreneur's risk-aversion coefficient $\gamma$. Thus, illiquid shares are worth less to economic agents who are more risk averse. This has important economic efficiency implications since the ability to bear portfolio risk is not necessarily the same as the ability to innovate. Thus, liquidity restrictions, such as those imposed by SEC Rule 144 that primarily impact start-ups and other young firms, can have the unintended effect of discouraging risk averse but otherwise innovative agents from forming new ventures.

The results in Table 1 also indicate that the ability to hedge the risk of illiquid stockholdings has an important effect on the implied value of restricted stock. When $\beta=0$ and the returns of the firm are uncorrelated with the market, the implied value of the restricted stock is significantly lower than when $\beta=1$. For example, in the case where $\gamma=4, \nu=0.30, \tau=5$, and $X=0.50$, the implied restricted stock value is 0.613 when $\beta=0$ but 0.702 when $\beta=1$. Similar results hold for other parameter values in the table. This underscores the importance of examining the costs of illiquidity within the context of a portfolio choice model that allows the entrepreneur to hedge using alternative liquid securities.

Finally, Table 1 shows that the implied value of restricted stock is decreasing in the volatility of the firm's returns. The reason for this is clear because an increase in $\nu$ implies that the undiversified illiquid position held by the entrepreneur is riskier without any compensating increase in its expected return (since $\beta$ is held constant).

\subsection{The optimal portfolio strategy}

Without liquidity restrictions, the Appendix shows that the entrepreneur would invest a constant fraction of his wealth in the stock market and would place the remainder in the risk-free asset. Thus, an unconstrained entrepreneur would not 
invest in the individual stock directly. Intuitively, this follows since the CAPM holds for the individual stock and the entrepreneur finds it optimal to invest in the diversified market portfolio rather than being exposed to the idiosyncratic risk of a position in the individual firm. This result is standard in traditional models of optimal portfolio choice. Note that by taking a position in the stock market, however, the entrepreneur has an indirect position in the firm's stock to the extent that it is a component of the market.

The entrepreneur's optimal portfolio behavior is significantly different in the presence of liquidity restrictions. As implied by the first-order condition in Eq. (9), the optimal portfolio weight $\phi^{*}$ depends in a complex way on the fraction of the entrepreneur's wealth that is tied up in restricted stock. For example, it is easily shown that the entrepreneur does not simply apply the unconstrained optimal portfolio strategy to the liquid portion of his portfolio. To show how liquidity restrictions affect the entrepreneur's portfolio strategy, Table 2 presents the optimal portfolio weights for the stock market, where the weight is expressed as a percentage of liquid (not total) wealth. Thus, Table 2 reports the portfolio weights $\phi^{*} /(1-X)$ for the same values of $\tau$ and $X$ as in Table 1 . Examples of these portfolio weights are also graphed in Fig. 2.

Table 2 shows that the presence of liquidity restrictions can have a major effect on the entrepreneur's optimal portfolio choice. For small values of $X$, the optimal portfolio weight is close to the optimal portfolio weight for the unconstrained case. As $X$ increases, however, the entrepreneur's portfolio weight quickly diverges from the unconstrained portfolio weight. When $\beta=1$ and the entrepreneur is able to partially hedge the risk of his illiquid position, the optimal portfolio weight can be substantially below the unconstrained weight. This is particularly true for shorter illiquidity horizons. In some cases, the presence of liquidity restrictions can lead to the entrepreneur actually taking a short position in the stock market, something that would not occur in the unrestricted case (when $\mu>0$ ). The reason for this is clearly due to the fact that the entrepreneur partially negates the effects of the constraint by taking a offsetting position in the stock market.

Interestingly, when stock market returns are uncorrelated with the firm's returns and $\beta=0$, the entrepreneur may still find it optimal to deviate significantly from the unconstrained portfolio weight. For example, when $\gamma=2, \beta=0, \nu=0.30, \tau=1$, and $X=0.70$, the entrepreneur places $178.1 \%$ of the liquid portfolio in the stock market. In the absence of liquidity constraints, however, the entrepreneur would place only $62.5 \%$ of the liquid portfolio in the stock market. This illustrates that the hedging motive is not the only reason why the constrained portfolio decision differs from the unconstrained case, since direct hedging is not possible when $\beta=0$. The intuition for why the entrepreneur takes a more aggressive stock market position when $\beta=0$ is related to a desire to smooth consumption over time. Recall that because of the risk of ruin, it is never optimal for the entrepreneur to consume out 
of illiquid wealth. On the other hand, when $\tau$ is small and $X$ is relatively large, the entrepreneur knows that it is very likely that there will be far more wealth available for consumption once the liquidity restriction lapses. In anticipation of this, the entrepreneur has an incentive to invest more aggressively in the short term in order to increase the expected value of his liquid wealth. By increasing the expected value of the liquid portion of his portfolio, the entrepreneur is able to increase the current consumption rate and partially reduce the size of the jump in consumption that is likely to occur when the liquidity restriction lapses.

As $\tau$ increases, the deviation of the optimal portfolio weight from the unconstrained case diminishes. The reason for this is that both the hedging and consumption smoothing motives for deviating from the unconstrained optimal are blunted as $\tau$ increases since the total variance of the value of the illiquid position becomes much larger relative to that of the liquid portfolio. Thus, the expected benefits of either hedging or consumption smoothing are swamped by the uncertainty in the final value of the restricted stock.

Interestingly, as $X$ increases towards one, the deviation of the optimal portfolio weight from the unconstrained weight converges back to zero. For some of the examples in Table 2, convergence isn't fully evident for $X=0.90$. In all cases, however, the convergence to zero is nearly complete for $X=0.99$. Thus, the greatest opportunities for hedging and consumption smoothing occur when the size of the liquid portfolio is on the same order as the size of the illiquid portfolio. As $X$ approaches one, the entrepreneur receives little benefit from either hedging or consumption smoothing. An alternatively way of thinking about this is by noting that $X$ is a state variable in the sense of Merton $(1969,1971)$. Hence, deviations from the unconstrained portfolio weight can be viewed as attempts to hedge the instantaneous risk of changes to the investment opportunity set caused by continuous stochastic fluctuations in $X$. As is easily shown by an application of Itô's Lemma, however, the instantaneous volatility of $X$ converges to zero as $X$ approaches either zero or one; the instantaneous volatility of changes in $X$ is greatest for intermediate values of $X$. Because of this, the largest deviation from the unconstrained case occurs when the volatility of the state variable $X$ is the largest, which happens for intermediate values of $X$. Finally, Table 2 shows that the portfolio weight is a decreasing function of the risk aversion parameter $\gamma$.

\subsection{Optimal consumption}

In this framework, the entrepreneur takes unlimited short positions in the liquid assets. Because of this, the entrepreneur could potentially maintain the same level of consumption over time that would be optimal in the absence of liquidity restrictions. From the first-order condition in Eq. (8), however, it is clear that the entrepreneur's optimal consumption rate will differ through its dependence on the portfolio weight $X$ for the restricted stock. 
To illustrate the effects of liquidity restrictions on optimal consumption, Table 3 reports the ratio of the optimal consumption rate in the restricted case to the optimal consumption rate in the unrestricted case. In addition, Fig. 3 plots the ratios for selected parameter values. As shown, a entrepreneur facing liquidity restrictions often finds it optimal to curtail consumption severely. For example, when $\tau=5$ and the illiquid stock represents $50 \%$ of total wealth, the entrepreneur consumes roughly $63 \%$ to $85 \%$ as much as one would in the absence of liquidity restrictions. When nearly all of the entrepreneur's wealth is in the form of restricted stock, the entrepreneur may actually consume less than $20 \%$ as much as one would otherwise.

Decreases in consumption of this magnitude clearly have major lifestyle implications for an entrepreneur who has most of his wealth in the form of illiquid stock. The larger the proportion of his wealth in the illiquid stock, the more the entrepreneur "tightens his belt" and limits his consumption. Thus, despite that the entrepreneur could maintain his level of consumption, the entrepreneur prefers to partially hedge the portfolio risk created by the restrictions by deferring consumption until the restrictions lapse. On the other hand, however, it is easily shown (by dividing the consumption ratios in Table 3 by $(1-X)$ ) that the entrepreneur consumes at a higher rate than if one had only liquid wealth and no restricted stock at all.

An increase in the length of the period of illiquidity generally reduces the entrepreneur's consumption rate. Interestingly, an increase in $\gamma$ does not always translate into a decrease in consumption, particularly when $X$ is relatively large. This is not altogether surprising since even in the unrestricted problem, optimal consumption is not a monotonic function of the risk-aversion parameter $\gamma$. In contrast, an increase in the volatility of the firm's returns generally results in a decrease in the optimal consumption rate. Finally, observe that when $\beta=1$ and the entrepreneur can partially hedge illiquid wealth through the stock market, the entrepreneur is typically able to consume at a higher rate than when $\beta=0$.

\section{Discussion}

These results have interesting implications for the important issue of how illiquidity affects financial assets. While it is important to acknowledge that we provide only a partial equilibrium analysis of the cost of liquidity restrictions, the results are at least broadly consistent with the empirical evidence of large discounts associated with illiquid securities. Wruck (1989) finds that private equity offerings for large publicly traded companies can be placed at discounts of as much as 15\%. Silber (1992) finds that restricted Rule 144 stock with a two-year trading restriction is privately placed at an average discount of $35 \%$ to otherwise identical registered stock. Amihud and Mendelson (1991) and Kamara (1994) find that the yields on illiquid 
Treasury bonds can be as much as 35 basis points higher than the yield on highly liquid but otherwise identical Treasury bills. Boudoukh and Whitelaw (1991) show that benchmark Japanese Government bonds trade at a large price premium to nonbenchmark bonds that are virtually identical. Brenner, Eldor, and Hauser (2001) find that illiquid currency options often sell for as much as $20 \%$ less than the price of their liquid counterparts. Longstaff (1992) finds that callable Treasury bonds can actually trade at a higher price than the portfolio of illiquid Treasury bonds which replicates an identical noncallable bond, effectively implying a negative value for the call feature. Longstaff (2001b) also shows a large time-varying liquidity component in the prices of Treasury bonds. THis component is related to measures of market sentiment such as consumer confidence and flows into stock and money market mutual funds. Theoretical models of the valuation effects of illiquidity on securities prices include Mayers (1972, 1973), Grossman and Laroque (1990), Boudoukh and Whitelaw (1993), Longstaff (1995), Vayanos (1998), Huang (1998), and Longstaff (2001a).

Our analysis also has implications for several areas of corporate finance. For example, our model suggests that restricted stock can be worth substantially less to an executive than it costs the issuing firm. A similar point is made in the existing literature on executive compensation packages, although this literature focuses primarily on stock options (see Lambert, Larcker, and Verrecchia, 1991; Rubinstein, 1995; Carpenter, 1998, 2000; and Hall and Murphy, 2000a, 2000b). Hence, our analysis lends support to the view that one reason why total CEO compensation is so high may be that the vast majority of it is in the form of restricted securities. Our calculations imply, however, that the illiquidity costs of restricted stock are larger than suggested in some of the earlier literature, and hence restricted stock is a less efficient form of compensation than commonly believed (see Hall and Murphy, 2000b). Although well beyond the scope of our paper, an interesting extension could be to solve for optimal contracts in a model that captures both the costs and benefits of liquidity restrictions. Such benefits might include reductions in agency costs.

Another implication, argue Amihud and Lev (1981), is that the high illiquidity costs of concentrated managerial equity holdings give managers a strong incentive to diversify their firms, perhaps through acquisitions, even if it is not in the interest of their shareholders. This is consistent with Morck, Shleifer, and Vishny (1990), who show that acquirer returns are negative if a firm acquires another firm in an unrelated business line.

Our model also has implications for the costs of concentrated ownership more generally, even if they are not caused by contractual or legal lockup periods. For example, IPOs help insiders cash out and hence diversify their portfolio by creating a more liquid market in the firm's shares. Thus, they reduce the costs of holding an undiversified portfolio and for this reason can be valuable to insiders. Because insiders put a high value on the diversification of their portfolios made possible by an 
IPO, they can take firms public earlier than is socially optimal. Moreover, they may accept a substantial amount of underpricing, as found in the empirical literature (for a summary, see Ibbotson and Ritter, 1995).

A related implication concerns private equity in general. For the U.S. owners of private equity earn no higher returns than the owners of public equity, although they have a much less diversified portfolio. More than $75 \%$ of private equity is owned by households for which this constitutes at least half of their wealth. Moreover, households with positive private equity invest on average more than $70 \%$ of their private holdings in a single firm in whose management they participate (Moskowitz and Vissing-Jorgensen, 2001). Presumably, these positions are held over a very long horizon. These findings give rise to a "private equity premium puzzle." Moskowitz and Vissing-Jorgensen (2001) do not calculate the costs associated with such a lack of diversification, but suggest that they can be large. Our paper offers one way to calculate these costs and confirms that they can be very large.

More generally, family ownership is in most countries the prevalent ownership structure, even for the largest publicly traded companies (La Porta, Lopez-deSilanes, and Shleifer, 1999). Our model suggests that the costs imposed on the family owners of these firms due to a lack of diversification can be very large, since they presumably hold their large positions for a long time. Hence, it suggests that the costs of weak shareholder protection, which can lead to highly concentrated ownership (La Porta, Lopez-de-Silanes, and Shleifer 1999), are very significant. These illiquidity costs of concentrated ownership should be taken into account in comparisons of financial systems that lead to widely differing degrees of ownership concentration. One could argue that the willingness of investors to hold these large blocks suggests that the positive effects of such concentrated ownership on corporate governance or the private benefits of control derived by the blockholders must be very substantial.

\section{Conclusion}

This paper studies the effects on stockholders of liquidity restrictions. These types of liquidity restrictions are imposed on many types of shareholders, but are particularly pervasive among stakeholders in new ventures such as entrepreneurs, venture capitalists, and private equity holders. To study these effects, we model the optimal consumption and portfolio choice problem from the perspective of an entrepreneur who is given restricted stock which cannot be sold for a fixed horizon. The entrepreneur can partially hedge the risk of the restricted stock by taking offsetting positions in the stock and bond markets.

Despite being able to trade in other securities, however, the economic costs to the entrepreneur of the liquidity restrictions can be very large. In some cases, the entrepreneur would actually prefer to sell his restricted stock for a small fraction of 
its market value. These costs are on the same order of magnitude as those shown executive stock options. The presence of liquidity restrictions also has major effects on the entrepreneur's optimal portfolio choice. When stock market returns are correlated with the returns on the firm's stock, the entrepreneur may invest far more (or far less) in the stock market than if there were no liquidity restrictions. Even when there is no correlation between the returns, however, the entrepreneur has incentives to take a more aggressive position in the stock market in order to smooth consumption over time. Liquidity restrictions can induce the entrepreneur to severely curtail his current consumption or lifestyle as an additional way of hedging the risk of his restricted stock. These results show clearly that an entrepreneur who may be a millionaire on paper (in the sense of owning a significant amount of restricted stock) behaves far differently from an entrepreneur with the same amount of wealth but without liquidity restrictions.

There are a number of possible directions for future research. In this paper, we focus exclusively on modeling the costs imposed by liquidity restrictions since the potential benefits of these restrictions in reducing agency costs, signalling information about the firm, and retaining key employees and managers are well understood in the literature. Clearly, however, it would be interesting to combine both strands of literature within a single model that would balance the costs and benefits and allow us to solve for optimal contracts. In addition, future research could examine the implications of liquidity restrictions within the context of a general equilibrium model in which some agents are not allowed to sell their shares and stock prices are endogenously determined (for example, see Mayers, 1972, 1973). 


\section{Appendix}

Using the definition of $X$, the dynamic budget constraint can be expressed as

$$
d W=(r W+\mu \phi W+\lambda N S-C) d t+\sigma \phi W d Z_{1}+\nu N S d Z_{2}
$$

Since $W$ and $S$ form a jointly Markov process, the derived utility of wealth $J(W, S, t)$ satisfies the Hamilton-Jacobi-Bellman equation

$$
\begin{aligned}
& \max _{C, \phi}\left[\frac{1}{2}\left(\sigma^{2} \phi^{2} W^{2}+2 \rho \sigma \nu \phi N S W+\nu^{2} N^{2} S^{2}\right) J_{W W}+\frac{1}{2} \nu^{2} S^{2} J_{S S}\right. \\
& +\left(\rho \sigma \nu \phi S W+\nu^{2} N S^{2}\right) J_{W S}+(r W+\mu \phi W+\lambda N S-C) J_{W} \\
& \left.+(r+\lambda) S J_{S}+J_{t}+e^{-\kappa t} \frac{C^{1-\gamma}}{1-\gamma}=0\right] .
\end{aligned}
$$

Differentiating Eq. (12) with respect to $C$ and $\phi$ gives the following first-order conditions

$$
C^{*}=\left(e^{\kappa t} J_{W}\right)^{-\frac{1}{\gamma}}
$$

and

$$
\phi^{*}=-\frac{\mu}{\sigma^{2}}\left(\frac{J_{W}}{W J_{W W}}\right)-\frac{\rho \nu S}{\sigma}\left(\frac{J_{W S}}{W J_{W W}}\right)-\frac{\rho \nu N S}{\sigma W} .
$$

We conjecture (and then verify) that the derived utility of wealth function is of the form

$$
J(W, S, t)=\frac{W_{t}^{1-\gamma}}{1-\gamma} F\left(\frac{N S}{W}, t\right)
$$

which implies that we can rewrite the derived utility of wealth as $J(W, X, t)$ by making a change of variables from $S$ to $X$. Differentiating this expression (via the chain rule) with respect to the variables $W, S$, and $t$ and substituting into the first-order conditions gives Eqs. (8) and (9). Note that Eqs. (8) and (9) imply that $C^{*} / W$ and $\phi^{*}$ depend on $W$ and $S$ only through $X$. Substituting Eqs. (8) and (9) into the Hamilton-Jacobi-Bellman equation and dividing through by $W^{1-\gamma} /(1-\gamma)$ gives 


$$
\begin{aligned}
& \frac{1}{2}\left(\rho \sigma \nu \phi^{*} X+\nu^{2} X^{2}\right)\left(-\gamma(1-\gamma) F+2 \gamma X F_{X}+X^{2} F_{X X}\right) \\
& +\left(\frac{\rho \sigma \nu}{2} \phi^{*} X+\nu^{2} X^{2}\right)\left(-\gamma F_{X}-X F_{X X}\right)+\frac{\nu^{2} X^{2}}{2} F_{X X} \\
& +\left(r+\frac{\mu \phi^{*}}{2}+\lambda X-\frac{C^{*}}{W}\right)\left((1-\gamma) F-X F_{X}\right)+(r+\lambda) X F_{X} \\
& +F_{t}+e^{-\kappa t}\left(\frac{C^{*}}{W}\right)^{1-\gamma}=0 .
\end{aligned}
$$

Observe that Eq. (16) depends only on $F(X, t)$ and its derivatives with respect to $X$ and $t$. Furthermore, $C^{*} / W$ and $\phi^{*}$ depend only on $F(X, t)$ and its derivatives with respect to $X$. Thus, our conjecture is verified if we can demonstrate that $F(X, t)$ is independent of $W$ on the boundaries.

To demonstrate this, we consider first the terminal condition at $t=\tau$ when the liquidity restriction lapses. Once the stock is no longer illiquid, then the manager's problem becomes a standard portfolio choice problem with two risky assets. The optimal portfolio strategy is given directly from Merton (1969) implying that the manager invests $\frac{\mu}{\gamma \sigma^{2}}$ in the stock market and zero in the stock. Thus, the problem reduces further to the case of a single risky asset. In this case, equation (26) of Merton (1969) implies that the unconstrained derived utility of wealth function $J(W, t)$ is of the form given in Eq. (10). This further implies that the unconstrained optimal consumption rate is

$$
C^{*}=W\left[\frac{\gamma}{\theta}\left(\left(1+\frac{\theta}{\gamma}\right) e^{\frac{\theta(T-t)}{\gamma}}-1\right)\right]^{-1}
$$

These results imply that $J(W, X, \tau)=J(W, \tau)$. Substituting into Eq. (15) then implies the terminal condition for $F(X, \tau)$. This terminal condition, along with the boundary conditions $F_{X}(0, t)=0$ and $F_{X}(1, t)=\infty$, implies that the function $F(X, t)$ does not explicitly depend on $W$, verifying the conjecture.

In solving for $F(X, t)$, we follow Brennan, Schwartz, and Lagnado (1997) and compute the function values numerically using a standard implicit finite difference technique. In particular, we linearize the partial differential equation for $F(X, t)$ in Eq. (16) by evaluating $C^{*} / W$ and $\phi^{*}$ using the estimated values of the function and its derivatives at time $t+\Delta t$. Since the variation in the values of $C^{*} / W$ and $\phi^{*}$ with respect to time is far smaller than the values of $F(X, t)$ and its derivatives, this linearization performs well. To insure the accuracy of this linearization scheme, however, we use extremely small steps in the time direction; the value of the function $F(X, t)$ is computed using 1,000 time steps per year (virtually identical results are obtained using smaller times, such as 10,000 steps per year). In this implicit finite difference scheme, we use 200 steps for the variable $X$. Thus, $X$ ranges from zero to one in steps of 0.005 . As a 
robustness check on the results, we also calculate the value of $F(X, t)$ using an explicit finite difference algorithm which does not require linearization since all derivatives with respect to $X$ are evaluated at time $t+\Delta t$. The results are virtually identical to those reported in the paper. 


\section{REFERENCES}

Aboody, D., 1996. Market valuation of employee stock options. Journal of Accounting and Economics 22, 357-391.

Amihud, Y., Lev, B., 1981. Risk reduction as a managerial motive for conglomerate mergers. Bell Journal of Economics 12, 605-617.

Amihud, Y., Mendelson, H., 1991. Liquidity, maturity, and the yields on U.S. treasury securities. The Journal of Finance 46, 1411-1425.

Bettis, J., Bizjak, J., Lemmon, M., 2001. Managerial ownership, incentive contracting, and the use of zero-cost collars and equity swaps by corporate insiders. Journal of Financial and Quantitative Analysis 36, 345-370.

Bettis, J., Coles, J.,Lemmon, M., 2000. Corporate policies restricting trading by insiders. Journal of Financial Economics 57, 191-220.

Brau, J., Lambson, V., McQueen, G., 2001. Why lockups? Unpublished working paper. Brigham Young University, Utah.

Brav, A., and Gompers, P.,2000, Insider trading subsequent to initial public offerings: evidence from expirations of lock-up provisions. Unpublished working paper. Duke University, North Carolina, and Harvard University, Massachussetts.

Brennan, M., Schwartz, E., Lagnado, R., 1997. Strategic asset allocation. Journal of Economic Dynamics and Control 21, 1377-1403.

Brenner, M., Eldor, R., Hauser, S., 2001. The price of options illiquidity. Journal of Finance 56, 789-805.

Boudoukh, J., Whitelaw, R., 1991. The benchmark effect in the Japanese government bond market. The Journal of Fixed Income September, 52-59.

Boudoukh, J., Whitelaw, R., 1993. Liquidity as a choice variable: a lesson from the Japanese government bond market. The Review of Financial Studies 6, 265-292.

Carpenter, J., 1998. The exercise and valuation of executive stock options. Journal of Financial Economics 48, 127-158.

Carpenter, J., 2000. Does option compensation increase managerial risk appetite? Journal of Finance 55, 2311-2331.

Dybvig, P., and Huang, C.F., 1988. Nonnegative wealth, absence of arbitrage, and feasible consumption plans. Review of Financial Studies 1, 377-401.

Field, L., Hanka, G., 2001. The expiration of ipo share lockups. Journal of Finance 56 
, 471-500.

Grossman, S., Laroque, G., 1990. Asset pricing and optimal portfolio choice in the presence of illiquid durable consumption goods. Econometrica 58, 25-52.

Hall, B., Murphy, K., 2000a. Optimal exercise prices for risk averse executives. American Economic Review, May, 209-214.

Hall, B., Murphy, K., 2000b. Stock options for undiversified executives. NBER Working Paper 8052.

Harrison, J., Kreps, D., 1979. Martingales and arbitrage in multiperiod securities markets. Journal of Economic Theory 20, 381-408.

Henderson, V., Hobson, D., 2001. Real options with constant relative risk aversion. Journal of Economic Dynamics and Control, forthcoming.

Hong, H., Huang, M., 2001. Newly public firms, illiquidity of insider stakes and investor relations. Unpublished working paper. Stanford University, California.

Huang, M., 1998. Liquidity shocks and equilibrium liquidity premia. Unpublished working paper. Stanford University, California.

Ibbotson, R., Ritter, J., 1995. Initial public offerings. In: Jarrow, R., Maksimovic, V., Ziemba, W. (Eds.), Handbooks in Operations Research and Management Science. Elsevier, Amsterdam, pp. 993-1016.

Kamara, A., 1994. liquidity, taxes, and short-term treasury yields. Journal of Financial and Quantitative Analysis 29, 403-417.

Kole, S., 1997. The complexity of compensation contracts. Journal of Financial Economics $43,79-104$.

Lambert, R., Larcker, D., Verrechia, R., 1991. Portfolio considerations in valuing executive compensation. Journal of Accounting Research 29, 129-149.

La Porta, R., Lopez-de-Silanes, F., Shleifer, A., 1999. Corporate ownership around the world. Journal of Finance 54, 471-517.

Longstaff, F., 1992. Are negative option prices possible? the callable U.S. treasury bond puzzle. The Journal of Business 65, 571-592.

Longstaff, F., 1995. How much can marketability affect security values? The Journal of Finance 50, 1767-1774.

Longstaff, F., 2001a. Optimal portfolio choice and the valuation of illiquid assets. Review of Financial Studies 14, 407-431. 
Longstaff, F., 2001b. The flight to liquidity premium in U.S. treasury bond prices. Unpublished working paper, University of California at Los Angeles, California.

Mayers, D., 1972. Nonmarketable assets and capital market equilibrium under uncertainty. In: Jensen, M. (Ed.), Studies in the Theory of Capital Markets. Praeger, New York, pp. 223-248.

Mayers, D., 1973. Nonmarketable assets and the determination of capital asset prices in the absence of riskless asset. Journal of Business , 46, 258-267.

Merton, R., 1969. Lifetime portfolio selection under uncertainty: the continuous time model. Review of Economics and Statistics 51, 247-257.

Merton, R., 1971. Optimum consumption and portfolio rules in a continuous time model. Journal of Economic Theory 3, 373-413.

Meulbroek, L., 2001. The efficiency of equity-linked compensation: understanding the full cost of awarding stock options. Financial Management Summer, 5-30.

Morck, R., Shleifer, A., Vishny, R., 1990. Do managerial objectives drive bad acquisitions? Journal of Finance 45, 31-48.

Moskowitz, T., Vissing-Jorgensen, A., 2001. The private equity premium puzzle. Unpublished working paper. University of Chicago, Illinois.

Ofek, E., Richardson, M., 2000. The ipo lock-up period: implications for market efficiency and downward sloping demand curves. Unpublished working paper. New York University, New York.

Osborne, A., 1982. Rule 144 volume limitations and the sale of restricted stock in the over-the-counter market. Journal of Finance 37, 505-517.

Rubinstein, M., 1995. On the accounting valuation of employee stock options. The Journal of Derivatives 3, 8-24.

Silber, W., 1992. Discounts on restricted stock: the impact of illiquidity on stock prices. Financial Analysts Journal, July/August, 60-64.

Vayanos, D., 1998. Transaction costs and asset prices: a dynamic equilibrium model. Review of Financial Studies 11, 1-58.

Wall Street Journal, 2001. Hedging their bets. J. Lublin, April 12.

Welch, I., 1989. Seasoned offerings, imitation costs, and the underpricing of initial public offerings. Journal of Finance 44, 421-449.

Wruck, K., 1989. Equity ownership concentration and firm value: evidence from private 
equity financings. Journal of Financial Economics 23, 3-28. 
Table 1

Implied value of restricted stock

This table reports the implied value of restricted stock as a fraction of its unrestricted market value. The implied value is calculated by solving for the fraction of the market value that a share of the firm's stock would need to sell for in the unrestricted case to give the same utility to the entrepreneur as achieved in the restricted case. The implied values are reported for an entrepreneur with varying fractions of wealth held in the form of stock that is illiquid for a period of $\tau$ years. The entrepreneur's risk-aversion coefficient is $\gamma$. The volatility and beta of the illiquid stock are $\nu$ and $\beta$ respectively. The riskless rate is $5 \%$, the expected premium on the stock market is $5 \%$, the volatility of returns on the stock market is $20 \%$, and the entrepreneur's final investment horizon is ten years. The rate of time preference equals the riskless rate.

\begin{tabular}{|c|c|c|c|c|c|c|c|c|}
\hline \multirow[b]{2}{*}{$\gamma$} & \multirow[b]{2}{*}{$\beta$} & \multirow[b]{2}{*}{$\nu$} & \multirow[b]{2}{*}{$\tau$} & \multicolumn{5}{|c|}{ Fraction of Illiquid Wealth } \\
\hline & & & & 0.10 & 0.30 & 0.50 & 0.70 & 0.90 \\
\hline \multirow[t]{3}{*}{2} & 0 & 0.30 & 1 & 0.990 & 0.972 & 0.954 & 0.936 & 0.887 \\
\hline & & & 2 & 0.979 & 0.941 & 0.906 & 0.865 & 0.669 \\
\hline & & & 5 & 0.929 & 0.828 & 0.719 & 0.536 & 0.212 \\
\hline \multirow[t]{3}{*}{2} & 0 & 0.60 & 1 & 0.959 & 0.894 & 0.838 & 0.783 & 0.705 \\
\hline & & & 2 & 0.909 & 0.795 & 0.706 & 0.620 & 0.472 \\
\hline & & & 5 & 0.730 & 0.541 & 0.420 & 0.306 & 0.152 \\
\hline \multirow[t]{3}{*}{2} & 1 & 0.30 & 1 & 0.995 & 0.984 & 0.974 & 0.964 & 0.931 \\
\hline & & & 2 & 0.988 & 0.967 & 0.946 & 0.923 & 0.720 \\
\hline & & & 5 & 0.962 & 0.900 & 0.818 & 0.605 & 0.222 \\
\hline \multirow[t]{3}{*}{2} & 1 & 0.60 & 1 & 0.964 & 0.905 & 0.854 & 0.803 & 0.735 \\
\hline & & & 2 & 0.920 & 0.815 & 0.732 & 0.650 & 0.506 \\
\hline & & & 5 & 0.760 & 0.576 & 0.454 & 0.335 & 0.165 \\
\hline \multirow[t]{3}{*}{4} & 0 & 0.30 & 1 & 0.981 & 0.946 & 0.913 & 0.881 & 0.828 \\
\hline & & & 2 & 0.959 & 0.892 & 0.833 & 0.773 & 0.556 \\
\hline & & & 5 & 0.877 & 0.730 & 0.613 & 0.444 & 0.148 \\
\hline \multirow[t]{3}{*}{4} & 0 & 0.60 & 1 & 0.924 & 0.817 & 0.730 & 0.645 & 0.541 \\
\hline & & & 2 & 0.845 & 0.680 & 0.565 & 0.458 & 0.322 \\
\hline & & & 5 & 0.617 & 0.412 & 0.300 & 0.208 & 0.103 \\
\hline \multirow[t]{3}{*}{4} & 1 & 0.30 & 1 & 0.989 & 0.969 & 0.949 & 0.929 & 0.861 \\
\hline & & & 2 & 0.977 & 0.936 & 0.897 & 0.850 & 0.568 \\
\hline & & & 5 & 0.927 & 0.820 & 0.702 & 0.480 & 0.148 \\
\hline \multirow[t]{3}{*}{4} & 1 & 0.60 & 1 & 0.932 & 0.833 & 0.751 & 0.671 & 0.568 \\
\hline & & & 2 & 0.859 & 0.703 & 0.590 & 0.485 & 0.343 \\
\hline & & & 5 & 0.643 & 0.437 & 0.321 & 0.224 & 0.108 \\
\hline
\end{tabular}


Table 2

Optimal portfolio weights

This table reports the optimal portfolio weight for the stock market, expressed as a fraction of total liquid wealth, for an entrepreneur with varying fractions of wealth held in the form of stock that is illiquid for a period of $\tau$ years. The entrepreneur's risk-aversion coefficient is $\gamma$. The volatility and beta of the illiquid stock are $\nu$ and $\beta$ respectively. The riskless rate is $5 \%$, the expected premium on the stock market is $5 \%$, the volatility of returns on the stock market is $20 \%$, and the entrepreneur's final investment horizon is ten years. The rate of time preference equals the riskless rate.

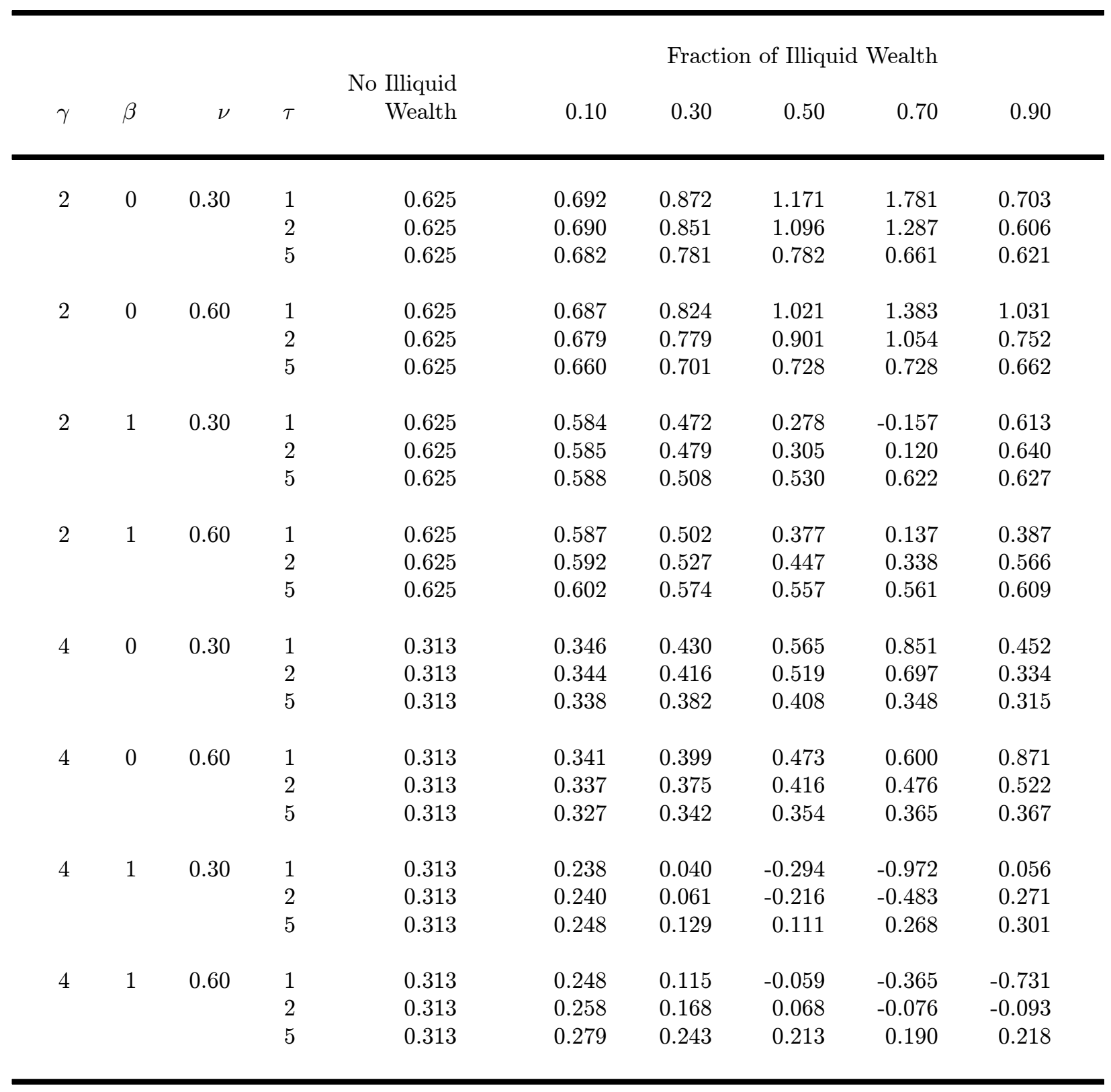


Table 3

Optimal consumption rates

This table reports the ratio of the optimal consumption rate for an entrepreneur with varying fractions of wealth held in the form of stock that is illiquid for a period of $\tau$ years to the optimal consumption rate in the unrestricted case. The entrepreneur's risk-aversion coefficient is $\gamma$. The volatility and beta of the illiquid stock are $\nu$ and $\beta$ respectively. The riskless rate is $5 \%$, the expected premium on the stock market is $5 \%$, the volatility of returns on the stock market is $20 \%$, and the entrepreneur's final investment horizon is ten years. The rate of time preference equals the riskless rate.

\begin{tabular}{|c|c|c|c|c|c|c|c|c|}
\hline \multirow[b]{2}{*}{$\gamma$} & \multirow[b]{2}{*}{$\beta$} & \multirow[b]{2}{*}{$\nu$} & \multirow[b]{2}{*}{$\tau$} & \multicolumn{5}{|c|}{ Fraction of Illiquid Wealth } \\
\hline & & & & 0.10 & 0.30 & 0.50 & 0.70 & 0.90 \\
\hline \multirow[t]{3}{*}{2} & 0 & 0.30 & 1 & 0.999 & 0.988 & 0.966 & 0.934 & 0.666 \\
\hline & & & 2 & 0.997 & 0.974 & 0.933 & 0.850 & 0.381 \\
\hline & & & 5 & 0.990 & 0.929 & 0.796 & 0.533 & 0.180 \\
\hline \multirow[t]{3}{*}{2} & 0 & 0.60 & 1 & 0.994 & 0.956 & 0.889 & 0.794 & 0.573 \\
\hline & & & 2 & 0.987 & 0.919 & 0.812 & 0.661 & 0.352 \\
\hline & & & 5 & 0.966 & 0.837 & 0.665 & 0.451 & 0.173 \\
\hline \multirow[t]{3}{*}{2} & 1 & 0.30 & 1 & 0.999 & 0.993 & 0.981 & 0.963 & 0.702 \\
\hline & & & 2 & 0.998 & 0.985 & 0.961 & 0.912 & 0.388 \\
\hline & & & 5 & 0.994 & 0.957 & 0.845 & 0.546 & 0.180 \\
\hline \multirow[t]{3}{*}{2} & 1 & 0.60 & 1 & 0.995 & 0.960 & 0.899 & 0.812 & 0.606 \\
\hline & & & 2 & 0.989 & 0.926 & 0.826 & 0.685 & 0.366 \\
\hline & & & 5 & 0.969 & 0.847 & 0.680 & 0.465 & 0.176 \\
\hline \multirow[t]{3}{*}{4} & 0 & 0.30 & 1 & 0.998 & 0.980 & 0.947 & 0.898 & 0.723 \\
\hline & & & 2 & 0.995 & 0.961 & 0.900 & 0.811 & 0.425 \\
\hline & & & 5 & 0.985 & 0.907 & 0.778 & 0.545 & 0.190 \\
\hline \multirow[t]{3}{*}{4} & 0 & 0.60 & 1 & 0.991 & 0.935 & 0.844 & 0.716 & 0.524 \\
\hline & & & 2 & 0.982 & 0.891 & 0.758 & 0.584 & 0.335 \\
\hline & & & 5 & 0.958 & 0.811 & 0.632 & 0.424 & 0.172 \\
\hline \multirow[t]{3}{*}{4} & 1 & 0.30 & 1 & 0.999 & 0.988 & 0.969 & 0.938 & 0.715 \\
\hline & & & 2 & 0.997 & 0.976 & 0.938 & 0.861 & 0.422 \\
\hline & & & 5 & 0.991 & 0.936 & 0.815 & 0.554 & 0.190 \\
\hline \multirow[t]{3}{*}{4} & 1 & 0.60 & 1 & 0.992 & 0.941 & 0.855 & 0.734 & 0.540 \\
\hline & & & 2 & 0.983 & 0.898 & 0.771 & 0.602 & 0.346 \\
\hline & & & 5 & 0.960 & 0.819 & 0.641 & 0.433 & 0.175 \\
\hline
\end{tabular}



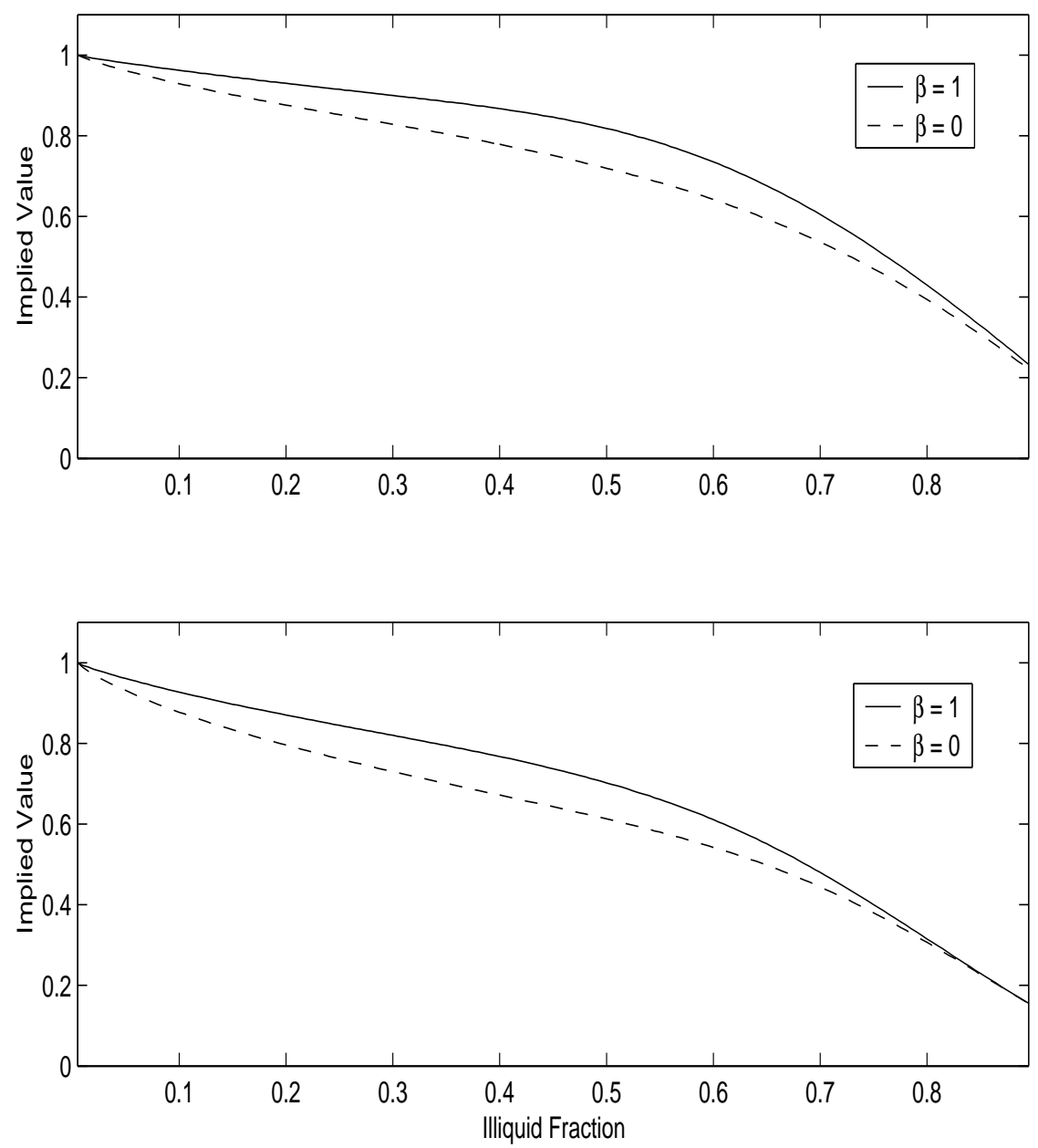

Figure 1. Implied Value of Restricted Stock as a Function of the Fraction of Illiquid Wealth. The parameter values for the graphs are stock volatility $(\nu)=.30$, interest rate $(r)=.05$, market risk premium $(\mu)=.05$, market volatility $(\sigma)=.20$, rate of time preference $(\kappa)=.05$, illiquidity horizon $(\tau)=5$ years, and investment horizon $(T)=10$ years. In the top panel, risk aversion coefficient $(\gamma)=2$; in the bottom panel, $\gamma=4$. 

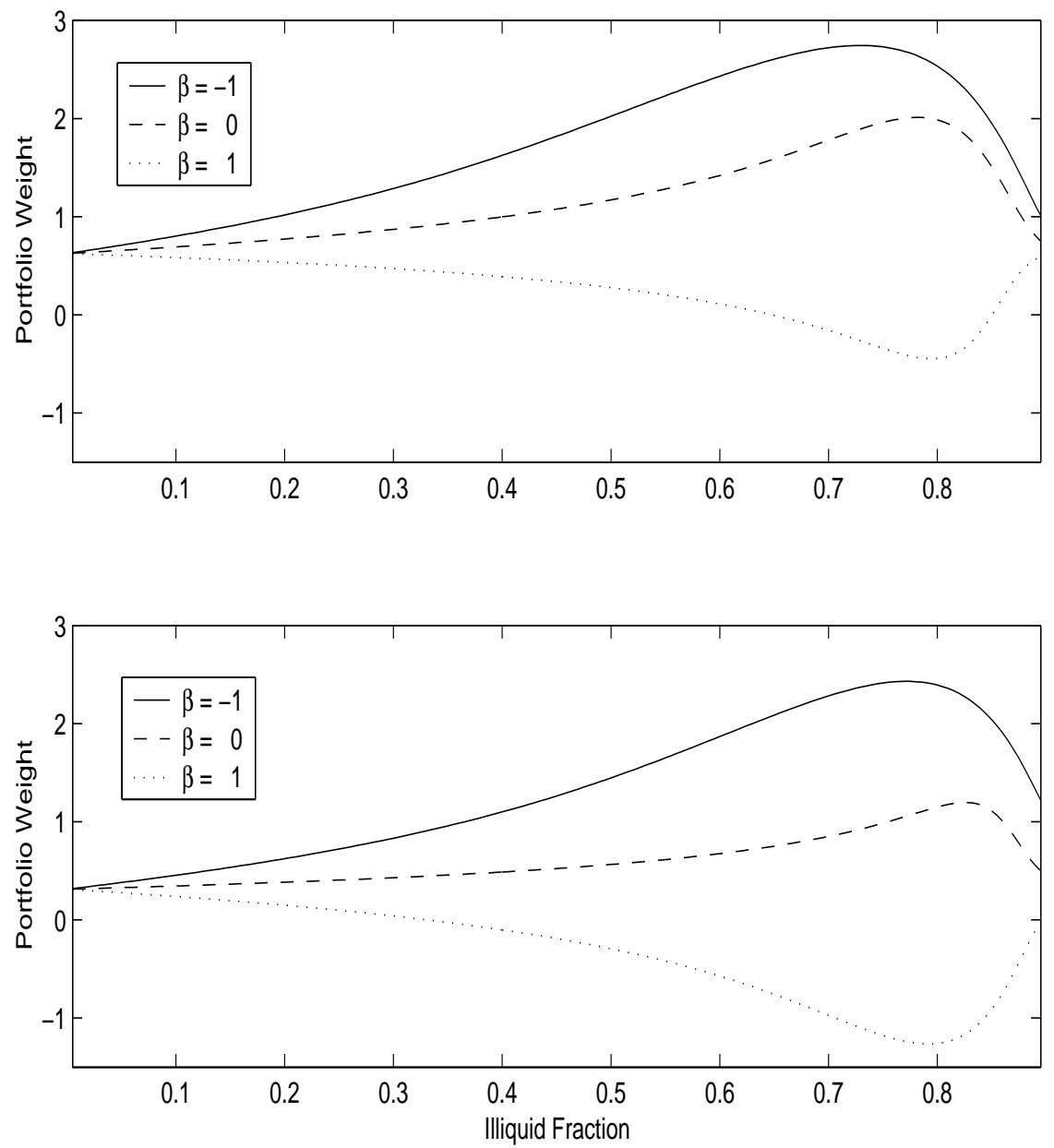

Figure 2. Optimal Stock Market Portfolio Weight (Relative to Liquid Wealth) as a Function of the Fraction of Illiquid Wealth. The parameter values for the graphs are stock volatility $(\nu)=.30$, interest rate $(r)=.05$, market risk premium $(\mu)=.05$, market volatility $(\sigma)=.20$, rate of time preference $(\kappa)=.05$, illiquidity horizon $(\tau)=5$ years, and investment horizon $(T)=10$ years. In the top panel, risk aversion coefficient $(\gamma)=2$; in the bottom panel, $\gamma=4$. 

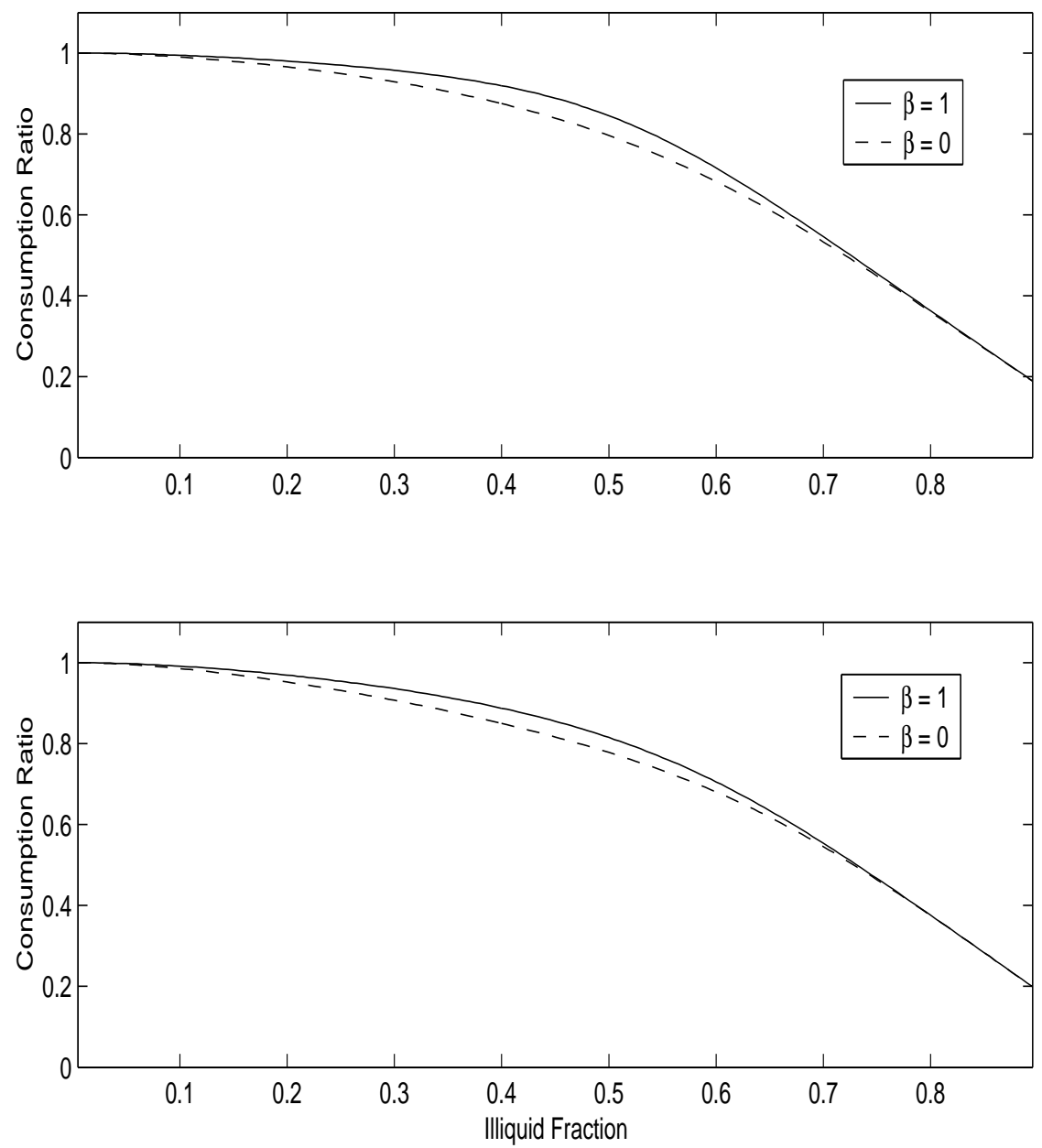

Figure 3. Optimal Consumption Ratio as a Function of the Fraction of Illiquid Wealth. The optimal consumption ratio is defined as the restricted consumption rate divided by the unrestricted consumption rate. The parameter values for the graphs are stock volatility $(\nu)=.30$, interest rate $(r)=.05$, market risk premium $(\mu)=.05$, market volatility $(\sigma)=.20$, rate of time preference $(\kappa)=.05$, illiquidity horizon $(\tau)=5$ years, and investment horizon $(T)=10$ years. In the top panel, risk aversion coefficient $(\gamma)=2$; in the bottom panel, $\gamma=4$. 